Sir,

\section{Bilateral diabetic papillopathy associated with optic} disc neovascularisation

Diabetic papillopathy is an uncommon condition characterised by transient visual dysfunction associated with optic disc swelling of otherwise unexplained aetiology. ${ }^{1}$ It usually occurs in the context of background diabetic retinopathy. ${ }^{2}$ We report a case of diabetic papillopathy associated with optic disc neovascularisation.

\section{Case report}

A 17-year-old Caucasian female with type 1 diabetes since 8 years of age was admitted to hospital with a 4 month history of blurred vision, and a 1 month history of transient visual obscurations, nausea, lethargy and mild weight loss. She denied headache or other neurological symptoms. She had a several-year history of poor diabetic control and episodes of diabetic ketoacidosis. However, significant improvement had occurred over recent months as indicated by $\mathrm{HbA}_{1 \mathrm{c}}$ levels of $6.3 \%$ on admission compared with $13.9 \% 4$ months previously.

On examination she was orientated, apyrexial and normotensive. General examination was normal.

Corrected visual acuities were 6/12 in each eye. She had no relative afferent defect, the anterior segments were normal and the intraocular pressures were $14 \mathrm{mmHg}$ in each eye. Fundoscopy showed bilateral florid disc neovascularisation associated with gross disc swelling and signs of widespread retinal ischaemia. Goldmann visual fields were normal. A full blood count, urea, electrolytes, vasculitis screen, liver and thyroid function tests, clotting screen, ESR, amylase, synacthen test, chest radiotherapy, brain CT scan and lumbar puncture (CSF pressure, microscopy, cytology and culture) revealed no abnormality.

She underwent fractionated panretinal photocoagulation (PRP), receiving approximately 1600 burns to each eye. One month later, her visual acuities had improved to $6 / 6$ in each eye, the disc swelling had partially resolved, but the optic disc new vessels persisted. These findings were confirmed by fluorescein angiography (Fig. 1), and a further 1600 PRP burns were applied. Three months later, visual acuities were 6/5 in each eye, and there was no evidence of disc

neovascularisation or disc swelling. Her diabetes control remained good during the treatment period with fructosamine levels ranging from 237 to $284 \mu \mathrm{mol} / 1$.

\section{Comment}

Diabetic papillopathy was described in 1971 in three teenaged patients with type 1 diabetes mellitus. ${ }^{1}$ Subsequent reports of the phenomenon in small case series $^{3-6}$ and a larger retrospective study ${ }^{2}$ have increased our understanding of this uncommon clinical entity.

Diabetic papillopathy can occur in type 1 and type 2 diabetics. It is more commonly bilateral than unilateral. Visual acuity is usually mildly to moderately reduced

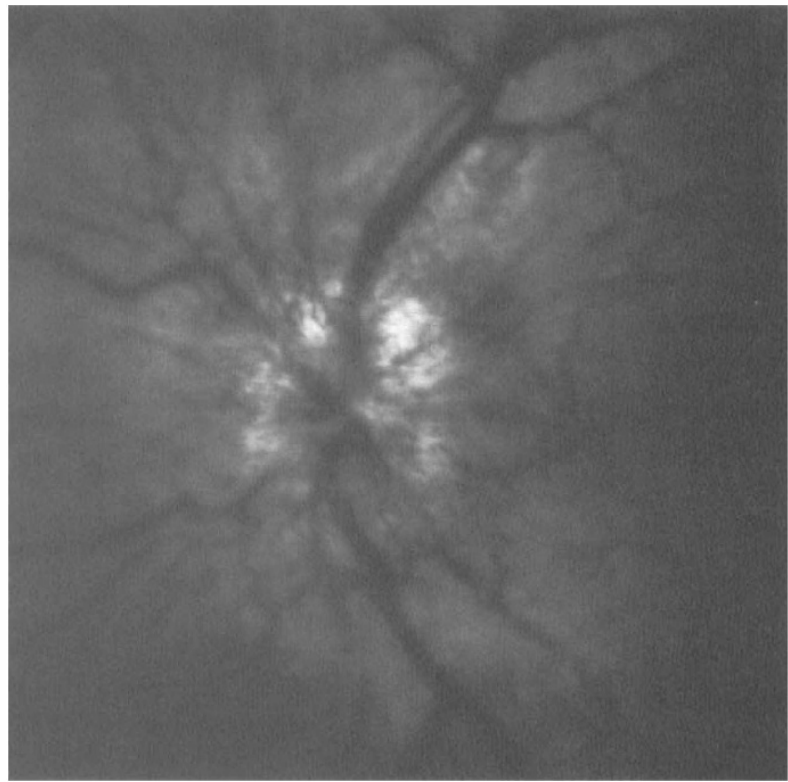

(a)

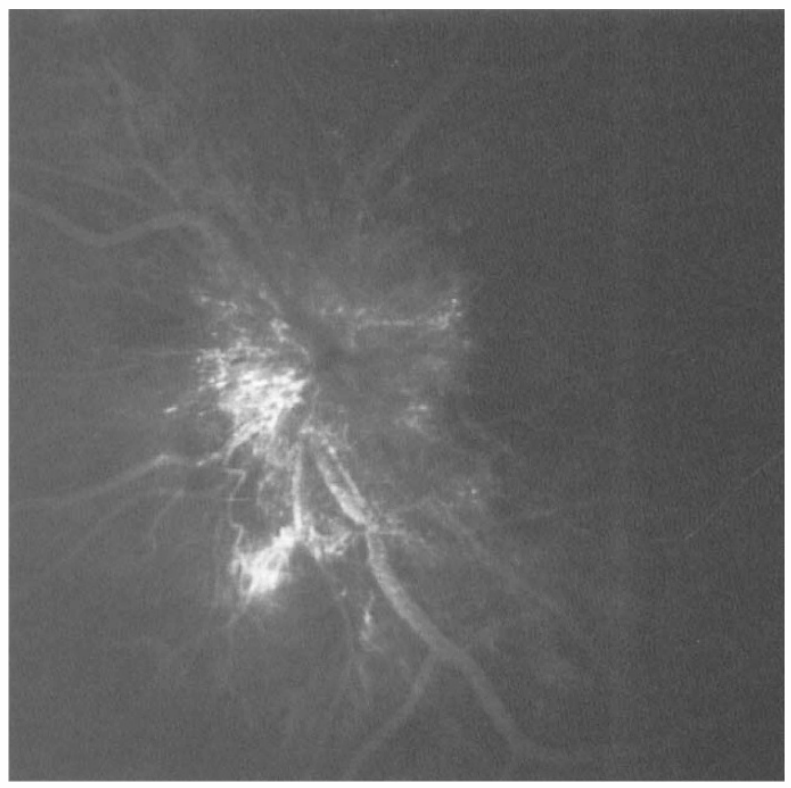

(b)

Fig. 1. (a) Red-free photograph showing mild disc swelling. (b) Fluorescein angiogram showing optic disc neovascularisation.

and tends to improve or remain stable. Relative afferent pupillary defects and dyschromatopsia may be elicited but are not typical. ${ }^{2}$ Visual field defects including enlarged blind spots, ${ }^{3,7}$ generalised constriction and arcuate scotomas ${ }^{2,5}$ may occur. The disc swelling, which resolves spontaneously after 1-10 months, is characteristically diffuse and hyperaemic and associated with prominent telangiectatic surface vasculature. ${ }^{2,3}$ Affected patients have also been observed to have a small optic cup:disc ratio. ${ }^{2,8}$ In most cases, diabetic papillopathy is associated with mild background diabetic retinopathy, with or without macular oedema. The underlying pathophysiology of the disc swelling is unclear. It has been proposed that small-vessel disease leads either to a superficial, retinal vascular disturbance 
with transient leakage of fluid into and around the optic nerve head ${ }^{3,4}$ or to deeper optic nerve head vascular compromise and axoplasmic flow disruption. ${ }^{1}$

Retinal new vessels are a recognised, if uncommon, clinical finding in patients with diabetic papillopathy, ${ }^{2,4-6}$ and non-perfusion has been demonstrated in up to $50 \%$ of patients using fluorescein angiography. ${ }^{2}$ However, associated disc

neovascularisation is rare: to our knowledge it has been reported in only three patients, occurring several weeks after the observation of diabetic papillopathy in each case. ${ }^{2,7}$ Our patient was unusual in presenting with signs of diabetic papillopathy and disc new vessels concurrently. In her case, the disc new vessels were clearly visible on slit-lamp biomicroscopy and were highlighted by the fluorescein angiography as shown in Fig. 1. However, in cases of less florid neovascularisation, distinction from the surface telangiectatic vessels characteristic of diabetic papillopathy may be more difficult and requires careful observation of the disc vessel pattern. New vessels of ischaemic origin tend to be more randomly orientated and elevated above the plane of the retina and disc, whereas the fine telangiectatic vessels of diabetic papillopathy are more radially orientated and lie within the disc and retina. Fluorescein angiography tends not to be helpful because profuse leakage from the disc vessels can occur in both conditions. $^{3}$

From a management standpoint, diabetic papillopathy should be a diagnosis of exclusion, following investigation of other causes of swollen discs. This report highlights the importance of careful funduscopy to identify coexisting severe diabetic retinopathy and, in particular, optic disc neovascularisation.

\section{References}

1. Lubow M, Makley TA. Pseudopapilloedema of juvenile diabetes mellitus. Arch Ophthalmol 1971;85:417-22.

2. Regillo CD, Brown GC, Savino PJ, Byrnes GA, Benson WE, Tasman W. Diabetic papillopathy: patient characteristics and fundus findings. Arch Ophthalmol 1995;113:889-94.

3. Appen RE, Chandra SR, Klein R, Myers FL. Diabetic papillopathy. Am J Ophthalmol 1980;90:203-9.

4. Pavan PR, Aiello LM, Wafai ZW. Optic disc oedema in juvenile-onset diabetes. Arch Ophthalmol 1980;98:2193-5.

5. Barr CC, Glaser JS, Blankenship G. Acute disc swelling in juvenile diabetes: clinical profile and natural history of 12 cases. Arch Ophthalmol 1980;98:2185-92.

6. Stransky TJ. Diabetic papillopathy and proliferative retinopathy. Graefes Arch Clin Exp Ophthalmol 1986;224:46-50.

7. Ho AC, Maguire AM, Yannuzzi LA, Fisher L, Galetta SL, Sergott RC. Rapidly progressive optic disc neovascularisation after diabetic papillopathy. Am J Ophthalmol 1995;120:673-5.

8. Josef JM, Burde RM. Ischaemic optic neuropathy of the young. J Clin Neuro-ophthalmol 1988;8:247-8.

Karl W. Whittaker

Jodbir S. Mehta

Marie D. Tsaloumas

Birmingham and Midland Eye Centre

Birmingham, UK
Mr K.W. Whittaker, FRCOphth

Birmingham and Midland Eye Centre

City Hospital NHS Trust

Dudley Road

Birmingham B18 7QH, UK

Sir,

Severe hypotony following cataract extraction in a patient on latanoprost

Latanoprost is a topical ocular hypotensive medication (prostaglandin $\mathrm{F}_{2 \alpha}$ analogue) which works via the uveoscleral pathway. ${ }^{1}$ To the best of our knowledge, choroidal detachment caused by latanoprost in a glaucoma patient following cataract surgery has not been described. We report the following case to illustrate a potential side-effect of latanoprost.

\section{Case report}

A 74-year-old man with a past ophthalmic history of uncontrolled primary open angle glaucoma, underwent a right trabeculectomy in 1994 and a repeated right trabeculectomy augmented with 5-fluorouracil in 1995. In 1997, his intraocular pressure (IOP) became uncontrolled at $26 \mathrm{mmHg}$. Latanoprost was then commenced, with a dramatic effect in reducing the IOP from 26 to $12 \mathrm{mmHg}$ in the right eye.

He underwent an uneventful right phacoemulsification with posterior implant under local anaesthetic in November 1999. The pre-operative visual acuity was 6/9 in the right eye with an IOP of $16 \mathrm{mmHg}$. His immediate post-operative period was unremarkable, with a visual acuity of $6 / 9$ and an IOP of $16 \mathrm{mmHg}$ on latanoprost and bethamethasone at 1 week. He presented 6 weeks post-operatively with a painful right eye.

Examination revealed a visual acuity of $6 / 24$ in the right eye and an IOP of $0 \mathrm{mmHg}$. The Seidel test was negative. The anterior chamber was deep and quiet. Fundal examination showed a large choroidal detachment in the supranasal and supratemporal areas. Latanoprost was discontinued and prednisolone $0.5 \% 4$ times a day was started in the right eye. Four weeks later, the visual acuity in the right eye recovered to $6 / 9$ with an IOP of 19 $\mathrm{mmHg}$, and a complete resolution of choroidal effusion. At 3 months follow-up his IOP in the right eye remained controlled at $12 \mathrm{mmHg}$ without treatment.

\section{Comment}

Our case illustrates a patient with poorly controlled glaucoma whose IOP stabilised on latanoprost treatment but who later developed profound hypotony following cataract extraction.

The pressure-lowering effect of phacoemulsification has been described in a number of studies, typically in the range of $1.1-2.5 \mathrm{mmHg}^{2}$ In another study, the pressure-lowering effect of phacoemulsification in glaucoma patients was not effective until a year later. ${ }^{3}$ The mechanism by which phacoemulsification lowers IOP is unclear, but it is thought to be related to the 